\title{
PROBLEMÁTICA DA ÁGUA SUBTERRÂNEA NO NORDESTE BRASILEIRO
}

Walter Duarte Costa

Professor da Universidade Federal de Minas Gerais 


\section{RESUMO}

O presente trabalho resultou da comparaçăo entre os resultados de poços tubulares abertos em uma região do nordeste brasileiro (estados do Rio Grande do Norte e Paraiba) e na regiåo sudeste, representada pelo estado de Minas Gerais.

Objetivou identificar as causas das grandes diferenças em termos quantitativos e qualitativos observadas nas águas explotadas de aquuiferos fissurais nas regiões de clima semi-árido e nas regiões de clima úmido.

Constatou-se que $\mathrm{em}$ ambas regiōes as vazões dos poços nesses aquuiferos estăo intimamente relacionadas com o comportamento de deformação das rochas cristalinas. Assim, as rochas de comportamento dúctil possuem fraturas mais fechadas porém pouco espaçadas, o que justifica as elevadas médias de vazões captadas em poços perfurados $\mathrm{cm}$ micaxistos e filitos. As rochas de comportamento rúptil possuem fraturas mais abertas porćm, em alguns casos, é muito grande o espaçamento entre fraturas. Assim, os gnaisses e quartzitos, que apresentam fraturas abcrtas e pouco espaçadas apresentam elevadas vazőes, enquanto os granitos, com fraturas abertas e muito espaçadas apresentam, em geral, vazóes mais reduzidas. Por outro lado, a qualidade dessas águas está relacionada com três fatores: possibilidade de renovaçấ, que depende das condições climáticas e topográficas; facilidade de fluxo subterrâneo, que depende da abertura das fraturas, dai serem mais salinizadas as águas de poços abertos $\mathrm{em}$ rochas dúcteis; $\mathrm{e}$ ausência de minerais altamente decomponiveis, como os feldspatos.

Concluiu-se que o fator determinante nas maiores diferenciações entre as duas regiões analisadas em termos de qualidade e quantidade das águas explotadas de aquiferos fissurais ć o clima. As maiores pluviosidades influem diretamente nas vazões por permitirem um maior volume de agua infiltrada e, indiretamente, por propiciarem a formação de solos residuais espessos, que acabam funcionando como um aquifero granular capeando o aquifero fissural. Por outro lade, uma recarga mais proficua promove uma continua renovaçào das águas infiltradas, reduzindo o risco de salinização das águas subterrâneas. A salinização é ainda acelerada nas regióes semi-áridas pelas elevadas temperaturas, que fazem subir à superficie os sais dissolvidos, através da evaporação intensa imposta às zonas mais superiores desses aqüíferos. 


\section{ABSTRACT}

This work resulted of the confrontation between the results of artesian wells achieved in a region of brazilian northeast (Rio Grande do Norte and Paraiba states) and in the southeast region represented by the Minas Gerais state.

Its objective was to identify the causes of the big differences in quantitatives and qualitatives terms that were observed in exploited waters of fissural aquifers in regions of semi-arid climate and regions of umid climate.

It was verified that in both regions, the discharges of the wells located in these aquifers are intimatement related with the deformation behaviour of the crystalline rocks. Therefore, the rocks of duptil behaviour have tighter fractures, however less spaced, what justifies the higher discharges of wells in schists and phylites. The rocks of ruptil behaviour have more opened fractures, however, in some cases, the spacing among fractures is much greater. So, the gnaisses and quartzites, that show opened and less spaced fractures, have greater discharges, while the granites, with opened and more spaced fractures have, in general, more reduced discharges. In other hand, the quality of these waters is related with three factors: possibility of renovation, that depends on the climatic and topographic conditions; facility of underground flow, that depends on the fractures' aperture, therefore the greater occurence of salty waters in wells of duptils rocks; and absence of minerals easily decomposed, as feldspars.

It was concluded that the decisive factor in the higher differenciations between the analysed regions in terms of quality and quantity of exploited waters of fisssural aquifers is the climate. The greater pluviosities influence directly in the discharges due to a bigger volume of infiltrated water and, indirectly, for allowing more residual soils to be formed, that act as a granular aquifer. In other hand, a bigger discharge enables a continous renovation of infiltrated waters, decreasing the risk of salinization of the ground waters. 


\section{HISTÓRICO}

O problema da escassez de água na regiăo nordeste do Brasil é secular e sobejamente conhecido em todo o pais.

Por conta da crucial sorte de um povo assolado pela seca $\mathrm{em}$ uma vasta área do território nacional, muitas soluçōes tểm sido aventadas e muita verba já foi alocada sem que o problema fosse resolvido.

É obvio que o problema não é simples, pois muitas condicionantes são envolvidas em função da extensâo regional $\mathrm{e}$ das consequientes diferenças físicas, sociais, institucionais e politicas ai reinantes.

Por isso mesmo, não se pode generalizar soluçōes para toda a região, como construir barragens em todo curso d'água ou abrir poços tubulares indiscriminadamente.

As criticas aos insucessos obtidos $\mathrm{cm}$ soluçốes generalísticas passa, peremptoriamente, pela falta de planejamento caracteristica de alguns programas tipicamente politicos que visam impressionar com números estratosféricos, priorizando a quantidade em detrimento da qualidade.

Uma das soluções que mais tem sofrido as agruras do inconsequiente tratamento dado ao problema é a abertura de poços tubulares.

Essa solução foi iniciada no século passado, com a criação do Instituto Federal de Obras Contra as Secas - IFOCS, precursor do Departamento Nacional de Obras Contra as Secas - DNOCS.

Ressentindo-se da falta de técnicos especializados que norteassem uma criteriosa locaçå̃o dos poços, esse órgăo passou mais de 70 anos abrindo "buracos" indiscriminadamente onde fosse solicitado.

Posteriormente, se somaram várias outras intervençōes a nivel federal, estadual e municipal, algumas delas de cunho tipicamente politico, onde os administradores do dinheiro público praticavam os ensinamentos de São Francisco (é dando que se recebe), trocando votos por poços.

As consequências desse descalabro podem ser sentidas no nòmero de poços secos existentes no nordeste. Embora năo haja um cadastro que forneça dados exatos, pois é grande o número de poços partículares que nem sempre såo levados ao conhecimento dos órglos pùblicos encarregados de gerir os recursos hidricos regionais, estima-se 
que, de um total aproximado de 60,000 poços existentes no nordeste, 3.000 sejam absolutamente secos, não contando ai aqueles que apresentam vazões irrisórias, ou águas imprestáveis pela elevada salinizaçâo.

É bem verdade que esse problema melhorou significantemente a partir da década de 60 , quando surgiram os primeiros geólogos formados em Pernambuco, muitos dos quais se devotaram à ciência responsável pelo cstudo da origem e captaçăo da água subterrânea, ou scja, a hidrogeologia.

Surgiu a SUDENE, como órgão destinado a desenvolver o nordeste à base de um racional planejamento; o DNOCS e as secretarias de estado foram paulatinamente se arregimentando para enfrentar mais tecnicamente o problema da perfuração de poços.

Já em 1961 criavam-se as primeiras normas e critćrios técnicos para locaçâo de poços em rochas cristalinas $\mathrm{c}$ as pesquisas que se seguiram permitiram a curto prazo reverter o quadro $\mathrm{c}$ a tradição de que abrir poço no nordeste representava um mero desperdicio do dinheiro público.

A SUDENE criou a Bacla Escola destinada a difundir as mais atualizadas técnicas de captação da água subterrânea, utilizando profissionais franceses, americanos, israclenses c alemães, além de equipamantos importados nesses paises. O nordeste criou tradição em hidrogeologia em todo o Brasil, fundando, em 1973, o primeiro curso de pós-graduaçåo "sensu strictu" em hidrogeologia. Do Curso de Geologia da UFPE sairam os mais renomados téenicos e professores que hoje lecionam essa ciência nos principais centros de ensino do pais.

Infelizmente náo foi ainda erradicado o "mal do poço seco" dessa regiło, face aos seguintes motivos: muitos fazendeiros não recorrem a qualquer órgâo técnico para orientá-lo quando desejam abrir um poço particular, procurando sempre executá-lo o mais próximo possivel de sua casa; alguns órgãos públicos, principalmente prefeituras, não possuem geólogos em seus quadros, coordenando em algumas àreas a abertura de um grande número de poços públicos $5 \mathrm{~cm}$ qualquer orientaçđo técnica; alguns projetos megalomaniacos e eleitoreiros ainda são praticados em alguns governos estaduais, programando um número de poços incompativel com a estrutura técnica disponivel pelo órgão; alguns poços ainda são distribuídos de forma política e para evitar a sua difusão, omitem qualquer participação técnica em sua cxecução. 
Esse histórico se fazia necessário para evitar comentários de desavisados sempre que se divulga cruamente os dados dos insucessos desse tipo de soluçăo. É possivel que o seu conhecimento possa acabar com indagações do tipo: "No nordeste năo há critérios técnicos para abrir um poço tubular?", ou, "Por que ainda se aplica dinheiro para abrir poço no nordeste se é grande a possibilidade de insucesso?".

\section{OBJETIVOS E CRITÉRIOS ADOTADOS}

O presente trabalho não visa dar nenhuma solução à problemática da àgua subterrânea no nordeste, nem diagnosticar as causas dos insucessos comentados no histórico procedido $\mathrm{em}$ sua abertura. Objetiva, simplesmente, fomecer uma contribuiçăo para o entendimento do complexo relacionamento entre as condicionantes naturais e antrópicas que interferem no resultado de um poço tubular.

Quando o autor publicou seu primeiro trabalho sobre o assunto (COSTA, 1965), constava, entre suas recomendaçðes, que deveriam ser analisados os resultados obtidos em outras regiōes e comparados com os obtidos para a regiăo estudada no estado da Paraiba, objetivando, principalmente, observar as influéncias exercidas por um clima diferente.

No presente trabalho esse cotejo é realizado a partir da análise de duas áreas pilotos escolhidas em duas regióes de clima bastante diferente: nordeste e sudeste.

No nordeste foi escolhida a área representada pelos estados do Rio Grande do Norte e da Paraiba, enquanto do sudeste foi escolhido o estado de Minas Gerais.

A escolha dos estados nordestinos acima referidos contou com as seguintes justificativas:

- esses estados somados possuem uma extensão de $107.124 \mathrm{~km}^{2}$,

- o conjunto situa-se na porçăo intermediária do nordeste;

- nesses estados reside uma das áreas de maior aridez do nordeste;

- essa região foi alvo da tese de doutorado do professor Waldir Duarte Costa, estando já todos os dados convenientemente tratados; 
A escolha do estado de Minas Gerais deveu-se às seguintes cauSas:

- esse estado representa $63,4 \%$ da área da região sudeste;

- por sua grande extensão territorial $\left(586,624,3 \mathrm{~km}^{2}\right)$, esse estado apresenta caracteristicas climáticas variadas, constituindo-se sua porçđ̃o norte, uma continuaç⿳亠丷厂 da regif́o nordeste em termos climáticos;

- o estado conta com um excelente banco de dados na COPASA (Companhia de Saneamento de Minas Gerais), que publicou recentemente o excelente trabalho "Disponibilidades Hidricas Subterrâneas no Estado de Minas Gerais".

- por ser tipicamente interiorano, esse estado exclui as anomalias morfo-climáticas caracteristicas do litoral, tomando mais semelhante sua posição geográfica $\mathrm{cm}$ relação à "área problemática do nordeste" que também exclui a parte litorânea.

\section{3. ÁREAS COTEJADAS E SUAS CARACTERÍSTICAS}

\section{1. - Nordeste Brasileiro}

O nordeste brasileiro năo se apresenta uniforme em termos de adversidade para àgua subterrainea.

Existem extensas àreas em que as condições climáticas ou geológicas favorecem a formaçțo de ricos mananciais hidricos subterrâneos, que sầo explorados com imenso sucesso para abastecimento público e irrigação.

Entre essas áreas, destacam-se as seguintes:

- Bacia do Parnaiba, nos estados do Piaui c Maranhão;

- Bacia do Potiguar, no Rio Grande do Norte;

- Bacia costeira Pernambuco-Paraiba;

- Bacia costeira Alagoas-Sergipe;

- Bacia do Recôncavo-Tucano-Jatobá, na Bahia e Pernambuco.

Nessas áreas nilo somente é elevada a pluviometria, como também é favorável a geologia para acumulação das águas infiltradas, já que se trata de rochas sedimentares, caracterizando excelentes aquiferos granulares. 
O problema do nordeste reside nas àreas interioranas constitui das por rochas cristalinas (magmáticas e metamórficas). Essa irea que apresenta uma extensão de $720,000 \mathrm{~km}^{2}$, ou seja, $46,3 \%$ de todo o nordeste, apresenta as seguintes características:

\section{a) Clima}

Os sistemas de circulação de ar que interferem no clima do nordeste são muito variados, ocorrendo correntes perturbadas nos quatro quadrantes que diversificam o sistema de chuvas, tornando complexa a caracterizaçăo climática dessa região. Assim, nào só é variado o periodo como a ćpoca de maior pluviosidade. Todavia, en termos médios, esse período é muito curto, de 1 a 2 meses (podendo inexistir) e ocorre no outono-inverno. A pluviometria anual na área mais problemática varia desde menos de $400 \mathrm{~mm}$, caracterizando um clima semiárido a árido, até um máximo de $800 \mathrm{~mm}$, variando sua maior extensẫo entre as taxas anuais de 500 e $600 \mathrm{~mm}$. As temperaturas médias anuais variam entre $20^{\circ} \mathrm{e} 28^{\circ} \mathrm{C}$, atingindo $40^{\circ} \mathrm{C}$ no Piaui na época do verão. A evapotranspiraçấo potencial é superior à precipitaçấo $\mathrm{cm}$ quase todo o ano, sendo ligeiramente inferior apenas em 1 ou 2 meses.

\section{b) Geologia}

Dominam essa área as rochas cristalofilianas précambrianas, com predominio das metamórficas e magmáticas ácidas. Assim, são mais comuns as seguintes rochas: gnaisse, micaxisto, filito, quartzito e mármore entre as metamórficas e granito, pegmatito e migmatito entre as magmáticas e metassomáticas.

\section{c) Solos}

O clima semi-árido que caracteriza essa regiăo năo favorece a intemperização das rochas. Por outro lado, as chuvas são concentradas em um curto periodo, ocorrendo geralmente em forma de enxurradas com alto poder erosivo, carreando facilmente os solos formados. Em conscquência, os solos eluviais são escassos no nordeste e apresentam reduzida espessura (máxima de $5 \mathrm{~m}$ ); quando existem, apresentam-se lixiviados e salinizados pela precipitação das águas evaporadas. A umidade desses solos é quase nula, como consequência do déficit hidrico resultante do balanço entre a pluviometria e a evaporaçĩo. 


\section{d) Relevo}

O relevo do nordeste é caracterizado por duas feições distintas: serras e planaltos isolados e depressōes. As serras e planaltos constituem diferenciaçōes geomorfológicas e revelam diferentes estágios de evoluçăo do relevo, decorrentes de interferéncias tectônicas combinadas com modificaçóes climáticas. Sua ocorrência é limitada aos divisores de estados e a alguns divisores hidrográficos orientados em direções variadas, mas predominantemente NE-SW. Suas cotas variam entre 300 e $500 \mathrm{~m}$, mas podem eventualmente atingir os $1.000 \mathrm{~m}$. As depressōes correspondem a maior parte da extensío nordestina, caracterizando uma superficie pediplanizada pelo predominio do intemperismo físico, com escoamento difuso e concentrado. Esse relevo é ondulado, com extensas áreas planas e com variações de cotas muito reduzidas.

\section{e) Hidrografia}

A rede hidrográfica do nordeste ć predominantemente intermitente, com cursos d'água retilineos, refletindo um severo controle estrutural, leitos rasos e rochosos, somente preenchidos por aluvião nos rios de maior porte. Muitos desses rios acham-se salinizados, principalmente quando suas cabeceiras coincidem com áreas de maior aridez. É que nessas áreas a evaporação é sempre superior à precipitação, estando os solos, na maior parte do ano, com deficiência de ảgua. Os sais trazidos de zonas mais profundas e precipitados no solo pela evaporaçẵo da água săo transportados pelas chuvas seguintes para os leitos dos rios, tornando salinizadas as suas águas.

\section{f) Área Piloto}

A área piloto escolhida do nordeste para a presente análise apresenta todas as caracteristicas acima referidas, podendo ser destacada uma feição geomorfológica/hidrográfica que é vista na figura 01. A área é dividida em dois segmentos de direção aproximadamente NS, por uma crista interfluvial que separa a drenagem dos dois cstados da seguinte forma: no segmento ocidental a drenagem se inicia nos limites dos estados PB/PE e se dirige para o norte, desembocando no Atlântico; no segmento oriental a drenagem se inicia nesse divisor e se dirige para o leste, desembocando também no Atlântico. A crista desse divisor coincide com a região de mais baixo indice de aridez dessa regiåo, o que justifica, pelo fato acima explicado, a presença de rios salinizados que nascem nesse divisor e que drenam o segmento oriental. 


\section{2. - Sudeste brasileiro}

O sudeste brasileiro constitui uma região de transição morfoclimática entre as regiठ̄es nordeste e sul do Brasil, muito cmbora guarde uma maior relação com as características do sul.

Também aqui, pode-se fazer uma distinção das caracteristicas físicas entre as áreas litorâneas e as árẹs interioranas, razão pela qual, nåo serẫo comentadas as primeiras.

A área interiorana do sudeste apresenta as seguintes caracteristicas:

\section{a) Clima}

Embora diversificado, o clima dessa regiào ć bem menos complexo que o do nordeste, pois somente ocorrem três sistemas de circulaçăo perturbada (E, W e S) e, ainda assim, com fraca atuaçăo na região interiorana da circulaçăo de $\mathrm{E}$. Constituí uma transiçâo dos climas quentes das baixas latitudes para os climas mesotérmicos das latitudes médias, embora suas caracteristicas sejam predominantemente de clima tropical. As chuvas dessa regiåo são trazidas principalmente pela circulação de oeste e a média anual varia entre $1.000 \mathrm{e}$ $1.500 \mathrm{~mm}$. O periodo de ocorréncia varia entre novembro e abril, porém, 30 a $50 \%$ se concentra em 3 meses, geralmente dez/fev, O periodo seco concentra-se no inverno, porém sua duração é muito variada, desde 1 até 6 meses. A temperatura média anual varia entre $20^{\circ} \mathrm{C}$ no limite SP/PR, até $24^{\circ} \mathrm{C}$ no norte de Minas. No verăo pode chegar a $32^{\circ} \mathrm{C}$ e no inverno pode ser negativa nas áreas mais elevadas.

\section{b) Geologia}

A geologia do sudeste não é muito diferente daquela já referida para o nordeste. Dominam as mesmas rochas précambrianas, com ênfase para as rochas metamórficas e metassomáticas. Apenas se acham presentes dominando o interior do estado de São Paulo e um reduzida faixa de Minas Gerais, as rochas básicas resultantes de extravasamentos terciários. No estado de Minas Gerais deve-se ressaltar a extensa ocorrência do Calcário Bambui, metamórfica migmatito que possui uma grande componente pelitica. 


\section{c) Solos}

As condições climáticas dessa regiăo favorecem o desenvolvimento do intemperismo químico, propiciando a formação de solos espessos, bem desenvolvidos e bastante diversificados, em função da rocha que Ihe deu origem. Os solos predominantes săo latossolo, podzólico e cambissolo e suas espéssuras variam em função da maior ou menor resistência à đecomposiçăo dos minerais presentes nas rochas e da declividade que favorece ou dificulta a infiltração das águas pluviais. São comuns também as formaçōes de coberturas detriticas correlacionadas aos estágios finais dos processos erosivos numa fase de peneplanização. Esses depósitos conformam chapadas ou peneplanos bem individualizados, semelhantes aos depósitos do Grupo Barreiras que margeiam o litoral brasileiro do Maranhão ao Rio de Janciro. A espessura desses depósitos pode ultrapassar os $100 \mathrm{~m}$, enquanto os solos residuais podem atingir os $50 \mathrm{~m}$ de espessura, sendo de $5 \mathrm{~m}$ a sua espessura minima.

\section{d) Relevo}

O relevo é muito variado na regiåo sudeste, caracterizando as seguintes feições morfológicas principais: Serras e Blocos compartimentados, onde dominam as Serras da Mantiqueira e do Mar, Planaltos, onde se destaca a Bacia do Paraná, que cobre parte dos estados de S.Paulo e Minas Gerais; Chapadas isoladas, consequientes de processos erosivos; depressరes com residuais, onde se destaca a Bacia do São Francisco.

\section{e) Hidrografla}

A rede hidrográfica dessa região é predominantemente perene, caracterizando-se por rios com grandes vazões, encaixados, com controle estrutural muito variado e geralmente providos de uma grande quantidade de aluvião, tanto em profundidade como em extensฐ̆o marginal.

\section{f) Área Piloto}

A área piloto escolhida, ou seja, o Estado de Minas Gerais, por sua grande extensão em relaçศ̆o à região caracterizada, possui praticamente todas as condicionantes naturais acima analisadas. Apresenta 
ainda uma boa possibilidade de comparaçẳo com o nordeste, por apresentar em sua extremidade norte, que delimita com aquela região, caracteristicas climáticas semelhantes, com uma acentuada queda na taxa pluviométrica, como mostra a figura 02

\section{4. - RELAÇÕES QUANTIDADE X QUALIDADE}

No trabalho publicado em 1965 este autor procedeu a uma série de correlaçठ̄es para justificar as variaçठ̄es constatadas nas vazões e na qualidade das águas de poços tubulares abertos na regiăo mais árida do estado da Paraiba (Sumé-Monteiro).

Essas correlações visaram definir melhores critérios para locação de poços tubulares em regiōes de rochas cristalinas, principalmente em climas semi-áridos, na tentativa não só de melhorar as vazð̋es que chegavam a ser nulas em muitos poços do nordeste, mas, também, evitar a abertura de poços imprestáveis pelo alto teor de salinizaçilo de suas águas.

Inúmeras outras pesquisas com a mesma finalidade foram desenvolvidas no nordeste, sendo dignas de registro as encetadas pelos geologos COSTA (1980, 1985 e 1986), CRUZ (1974), LEAL (1968), MENDES et alli (1980), REBOUÇAS (1973) e SIQUEIRA (1963).

Praticamente não evoluiram muito as conclusões sobre as correlações iniciais, apenas tendo sido corroboradas com consideraçסes no âmbito da mecânica das rochas, feitas pelo próprio autor e por COSTA, além de algumas análises climáticas restritas à região nordeste.

Presentemente tencionamos extrapolar as correlações já conhecidas a outra regiåo do Brasil a fim de avaliar melhor a influência do clima nessas correlações e poder explicar melhor as causas de insucessos na perfuraçào de poços no nordeste.

\section{1. - Influências dos fatores endógenos}

Como fatores endógenos serão consideradas todas as condicionantes naturais relacionadas com o local em que o poço é perfurado. Inclui, assim, o tipo litológico, o manto de alteração e as estruturas do maciço rochoso. 


\subsection{1. - Tipo de Rocha}

\section{a) Quantidade}

É sabido que as rochas cristalofilianas constituem o aquifero denominado fissural, onde a água tem sua circulação restrita às fraturas ou fissuras do maciço rochoso, já que a porosidade intersticial é praticamente nula nessas rochas.

Assim, a potencialidade desse tipo de aquifero depende de dois fatores: densidade e abertura das fraturas.

A densidade é importantissima pois o reduzido espaçamento entre as fraturas facilita a intercomunicaçăo da água através de diferentes tipos de fraturas, chegando ao ponto de impingir ao aqüifero fissural um comportamento de aquifero granular, quando esse espaçamento é minimo.

A abertura é importante por facilitar o fluxo da água subterrânea, sendo tal fator o principal determinante da permeabilidade desse tipo de aquifero.

Nesse contexto, é fundamental conhecer o comportamento ruptural de cada tipo rochoso, a fim de avaliar a sua potencialidade como aquíifero.

Em principio, as rochas competentes, ou seja, que assumem um comportamento rúptil ao serem solicitadas por esforços, tendem a sofrer ruptura sem que nenhuma deformação plástica ocorra. Como resultado, as fraturas são mais abertas, todavia, podem apresentar um espaçamento muito variado. Como exemplo temos o granito, que possui fraturas abertas, porém, geralmente muito espaçadas; os gnaisses, que apresentam fraturas abertas e com espaçamento médio; os quartzitos, com grandes aberturas e reduzido espaçamento de fraturas; c os basaltos, com comportamento semelhante aos quartzitos.

As rochas incompetentes săo aquelas que possuem um comportamento dúctil ao serem solicitadas por esforços, sofrendo deformações plásticas antes de sofrerem nupturas. Essas rochas apresentam geralmente fraturas mais fechadas, porém, a densidade sempre é grande, ou seja, é muito reduzido o espaçamento entre fraturas. Como exemplo nas regiōes estudadas, ocorrem os micaxistos e os filitos. 
Os calcários metamorfisados apresentam um comportamento dúctil-frágil, ou seja, intermediário entre o dúctil e o ríptil, todavia, a circulação da água nessas rochas assume especificidades muito variadas em decorrência da dissoluçăo química que tende a aumentar a abertura das fraturas até o limite de transformar uma fratura em uma caverna.

Em funçâo do exposto, pode-se obscrvar a grande influência que os diferentes tipos litológicos exercem na hidrogeologia do cristalino, analisando os resultados sobre a quantidade das águas extraidas de 843 poços analisados no nordeste e 1227 poços de Minas Gerais.

No nordeste pode-se observar a nítida influência das considerações acima feitas sobre a potencialidade dos aquifferos fissurais, através da análise do Quadro II. A vazão especifica do gnaisse foi a mais elevada, em consequiència da maior abertura de suas fraturas, vindo logo a seguir o quartzito e o micaxisto, quase igualados, o primeiro graças principalmente à abertura de suas fraturas, enquanto o micaxisto tem no reduzido espaçamento de suas fraturas a razấo de sua boa potencialidade. Os filitos vêm a seguir, graças, também, ao seu reduzido espaçamento de fraturas, vindo por último o conjunto granitomigmatito, que apresentam fraturas abertas porém com grande espaçamento.

Verifica-se que, relativamente, a influéncia da densidade das fraturas foi maior que a sua abertura na análise procedida na região nordeste.

O mesmo fato pode ser observado em Minas Gerais, pelos dados do Quadro V. Entre os aquiferos fissurais as seguintes rochas apresentaram maior potencialidade na ordem decrescente: pelitos, basalto, quartzito, micaxisto e granito-gnaisse. Observe-se que as 4 primeiras rochas têm sua potencialidade hidrica relacionada com a densidade do fraturamento, enquanto as últimas rochas são aquelas em que a vazão depende mais da abertura das fraturas (no caso, o conjunto foi influenciado negativamente pela baixa densidade do granito).

Constata-se, assim, que também na regiấo sudeste a densidade das fraturas influiu mais do que a sua abertura na potencialidade dos aquiiferos fissurais.

Deixamos de analisar os aquiiferos granulares e os carbonáticos por não representarem problema para água subterrânea em qualquer parte do pais. 


\section{b) Qualidade}

A salinização das águas subterrâneas decorre da dissolução de minerais mais solúveis que constituem as rochas, pelo contato das águas infiltradas ao longo das fraturas. Evidentemente, esse processo é lento e depende de uma série de fatores relacionados com a resistência de cada mineral e do grau de acidez das águas percoladas (função da salinização dos solos de cobertura, grau de lixiviaçío, presença de humus, etc), bem como, do grau de salinização das águas infiltradas diretamente dos rios já salinizados.

Quando as àguas infiltradas são isentas de sais, o ataque aos minerais vai progressivamente enriquecendo de sais as àguas armazenadas, principalmente nos dois seguintes casos:

- a renovaçào das águas é deficiente (clima semi-árido);

- as fraturas são muito fechadas, dificultando a percolação da água c sua conseqüente renovaçăo.

No primeiro trabalho do autor (1965) foram procedidas algumas relações entre os diferentes sais encontrados nas águas subterrâneas e os minerais presentes nas rochas que funcionavam como aqũifero. Foi constatado que os feldspatos eram um dos principais responsáveis pela liberaçẫo de sais, $\mathrm{cm}$ funçăo da maior facilidade como são atacados pela àgua. Nesse caso, os migmatitos, pegmatitos c alguns granitos e gnaisses poderiam apresentar maior propensão para salinização das ảguas.

Por outro lado, as rochas de comportamento dúctil, como os micaxistos e os filitos, apresentam fraturas muito fechadas, que poderiam dificultar a percolaçîto da água, aumentando o tempo de contato entre a água e os minerais, com a conseqüente possibilidade de maior dissolução desses minerais e salinização dessas águas.

Observando o Quadro II, pode-se constatar alguma cocrência entre as afirmaçồes acima expostas para o caso do nordeste brasileiro.

Assim é que, o migmatito, pelo seu predominio de feldspato, apresenta uma elevada salinizaçăo como aqüifero, o mesmo ocorrendo com os gnaisses, que provavelmente deveräo ser ricos em feldspatos; 0 micaxisto, por sua reduzida abertura de fraturas também apresenta elevada salinizaçầo das águas que armazena; o quartzito, pela ausência de minerais decomponiveis e regular abertura de suas fraturas, deveria apresentar uma melhor qualidade; o filito pode ser considerado um 
resultado anômalo, pois suas fraturas com reduzida abertura deveriam propiciar uma maior salinização das águas ai armazenadas.

Deve-se, todavia, considerar que a salinizaçăo dos poços do nordeste tem várias outras causas, que serão comentadas nos itens seguintes, que mascaram as relaçōes acima tentadas.

Já na regiåo sudeste, pode-se constatar, no Quadro V, que as rochas do sistema fissural apresentam a seguinte ordem decrescente de salinização: micaxisto, quartzito, pclitos, granito-gnaisse e basalto.

Em toda essa seqũência, consideramos como anómalo c inexplicável a posição do quartzito, pois deveria ser o aquifero menos salinizado pelas razőes já discutidas. Todas as demais rochas apresentam um posicionamento coerente com as relaçठ́es acima expostas.

Em resumo, as rochas de comportamento dúctil podem se constituir bons aquiferos em termos quantitativos, mas nem sempre săo confiáveis sob o ponto de vista qualitativo.

\subsection{2. - Tipo de Estrutura}

\section{a) Quantidade}

Foi dito no item precedente que as fraturas abertas propiciam uma maior facilidade ao escoamento das águas subterránens, aumentando a possibilidade de captar maiores vazões. Por outro lado, essa maior facilidade de percolação propicia uma maior renovaçâo dessas águas, reduzindo o risco de salinizaçăo.

Assim, é muito importante perscrutar a possibilidade de captar fraturas que, por sua própria gênese, possuam maior possibilidade de se encontrarem abertas.

A relação entre vazão e tipo de fratura foi também cstudada desde 1965 pelo autor, que ampliou essas relações com o auxilio da mecánica das rochas para explicar a gênese do fraturamento.

Em principio, as fraturas originadas por traçẫo (tanto paralelas à foliaçăo, ou longitudinais, quanto transversais à mesma) são as que apresentam maior possibilidade de se encontrarem abertas, enquanto aquelas originadas por cisalhamento săo, pela própria génese, praticamente fechadas. 
No Quadro III pode-se observar a relação entre a vazăo e os tipos de fraturas para a área piloto escolhida para o nordeste.

Enquanto os poços perfurados em fraturas de traçắo acusaram médias de vazão especifica de $0,298 \mathrm{1} / \mathrm{s} / \mathrm{m}$ para as transversais e 0,134 $\mathrm{l} / \mathrm{s} / \mathrm{m}$ para as longitudinais, as fraturas de cisalhamento propiciaram médias de vazões especificas de $0,031 \mathrm{~L} / \mathrm{s} / \mathrm{m}$ para as angulares e 0,029 $\mathrm{l} / \mathrm{s} / \mathrm{m}$ para as longitudinais. Deve-se observar ainda que nos poços locados em áreas onde nåo foram observadas fraturas ( 50 poços) a média da vazão específica foi de apenas $0,0191 / \mathrm{s} / \mathrm{m}$.

Para o estado de Minas Gerais não há informaçóes sobre esse tipo de relaçăo.

\section{b) Qualidade}

Comprovando a assertiva feita de que as fraturas de abertura reduzida sâo mais favoráveis à salinizaçåo das águas nelas contidas, pode-se observar no Quadro III que a média dos sólidos totais para poços abertos em fraturas de tração é de $2.226 \mathrm{mg} / \mathrm{l}$, enquanto para as fraturas de cisalhamento essa média passa para $3.874 \mathrm{mg} / 1$ ( $73 \%$ a mais), chegando a $5,072 \mathrm{mg} / 1$ para as fraturas longitudinais de cisalhamento.

\subsection{3. - Manto de Alteração}

O manto de alteração ou capeamento é conseqüente da alteraçăo "in situ" do maciço rochoso ou do preenchimento de depressøes com material detrítico na fase final de um ciclo erosivo, conforme referido no item 3.2.

A constituição e espessura desses materiais varia de acordo com as condiçøes de intemperismo e da natureza da rocha que lhe deu origem.

Em termos hidrogeológicos esse capeamento pode apresentar, cm função de sua espessura e textura, duas importantes influências para a captaçăo de água subterrånea no substrato rochoso:

- pode funcionar como um aquifero granular e, nesse caso, um poço perfurado de forma a atravessar todo esse capeamento e penetrar no substrato rochoso irá captar água simultaneamente do aquifero superior (granular) e do aquífero inferior (fissural); 
- mesmo que năo funcione como aqüifero, esse capeamento pode ajudar na distribuiçào das águas através das fraturas, direcionando toda a parcela de águas pluviais infiltradas para todas as fraturas que se comuniquem com tal capeamento.

No nordeste, o capeamento é nulo em mais de $50 \%$ dos poços existentes, sendo de $3,17 \mathrm{~m}$ a espessura média dos solos formados. No Quadro I observa-se que a média de profundidade do nivel freático é de $4,87 \mathrm{~m}$, ou seja, já no embasamento rochoso, o que indica estar o solo de cobertura completamente seco. Por outro lado, os solos pouco espessos e lixiviados tendem a reter os sais consequentes da evaporação das águas infiltradas mesmo antes de atingirem as fraturas do maciço rochoso, tornando os poucos solos formados altamente salinizados nas áreas de maior aridez.

Já no sudeste, foi mencionado no item 3.2a, que a cobertura pode atingir a $50 \mathrm{~m}$ nas encostas e ultrapassar a $100 \mathrm{~m}$ nas depressōes, - que é corroborado pelo Quadro V, onde o aqüifero constituido pelo conjunto de cobertura detritica c cluvião possui uma profundidade média de captação por poço de $77 \mathrm{~m}$ e sua vazão especifica média é de $0,31 \mathrm{l} /$ $\mathrm{s} / \mathrm{m}$, ou seja, superior a qualquer aquifero fissural do nordeste. Assim, os poços existentes na regiåo sudeste contam com duas contribuiçōes em termos de água subterrânea, sendo, muitas vezes, a contribuição do capeamento superior à do substrato rochoso.

\section{2. - Influências dos fatores exógenos}

Como fatores exógenos serão consideradas todas as condicionantes alóctones, ou seja, que năo se relacionam diretamente com as características do aquífero captado. Entre eles destacam-se o clima e relevo/hidrografia.

\subsection{1. - Clima}

\section{a) Quantidade}

A potencialidade de um aquifero fissural depende de três condicionantes: capacidade de armazenamento, condiçōes de recarga c disponibilidade de água infiltrada.

A capacidade de armazenamento diz respeito unicamente às condicionantes do aquífero e já foram analisadas nos fatores endógenos. 
A condição de recarga depende, em parte, das caracteristicas de relevo e hidrografia, a serem tratadas no item seguinte. Todavia, grande parte dessa condiçăo está relacionada ao capeamento do maciço rochoso, como já foi mencionado no item anterior. Ocorre que, o fator determinante na profundidade ou espessura do manto de cobertura é o clima. Com efeito, pode ser observado que as rochas presentes no sudeste sằo as mesmas que ocorrem no nordeste $\mathrm{e}$ a formaçẳo do manto de alteraçăo é completamente diferente, em decorrència das diferenças climáticas jả referidas.

Finalmente, as disponibilidades de água infiltrada sấo consequeentes da pluviosidade, considerando condições de textura do solo e relevo semelhantes.

Considerando que a pluviosidade média do sudeste é $\mathrm{cm}$ tomo de $130 \%$ superior a do nordeste, não é de estranhar que a vazão media dos aquiiferos fissurais naquela região seja quase $200 \%$ superior a desta, principalmente se considerar a influência dos demais fatores já analisados.

Em resumo, o clima tem uma dupla influência para a potencialidade de um aquífero fissural: influi diretamente, $\mathrm{cm}$ funçào do volume infiltrado, que depende da pluviometria; indiretamente, influi na formação do solo residual, que poderá funcionar como um aquifero complementar.

\section{b) Qualidade}

A principal influência do clima diz respeito ao balanço hídrico entre as taxas de pluviometria e evapotranspiração potencial.

Nos climas semi-áridos, como no nordeste, essa relação favorece a precipitaçấo de sais pelas águas evaporadas, deixando os solos superficiais altamente salinizados. As chuvas que se sucedem carreiam em soluçăo esses sais com dois destinos diferentes: alimentam os rios através do escoamento superficial e os aquifferos através da parcela de àgua infiltrada diretamente, ao longo das encostas, ou indiretamente, através dos próprios rios.

Esse fato pode ser observado na área piloto do $\mathrm{NE}$, através da análise do Quadro IV, que mostra uma salinização média das águas de poços na parte oriental dessa área com ST $=5.581,70 \mathrm{mg} / \mathrm{l}$, enquanto na parte ocidental esse valor cai para $1.436,20 \mathrm{mg} / \mathrm{l}$. Considerando que os rios da parte oriental têm suas cabeceiras na faixa mais árida da 
regiầo, conforme mostra o mapa da figura 01, esses altos valores de salinização das águas subterrâncas são justificados pela alimentação que esse aquifero recebe dos rios salinizados que drenam essa área (COSTA, 1986).

Na regî́o sudeste o clima é caracterizado por uma elevada pluviosidade, que excede a evapotranspiraçilo potencial durante quase todo o ano.

Consequentemente, os valores médios representativos da salinizaçtio das águas dessa região são baixíssimos, tendo praticamente todos os rios água de excelente qualidade. Também a água subterrânea é de boa qualidade, sendo de $217,29 \mathrm{mg} / \mathrm{l}$ a média de sólidos totais dissolvidos, com o maior valor médio por aquifero de apenas 349,53 (aquífero xistoso), ou seja, valores 15 vezes menores, em média, aos obtidos no nordeste.

Um fato curioso, que mostra muito bem a influência do clima na salinização das águas subterrâneas pode ser constatado na comparaçílo dos mapas das figuras 02 e 03, ambas referentes ao Estado de Minas Gerais.

A regiăo NE desse estado corresponde às áreas de mais elevado teor de salinização das águas subterrâneas (condutividade elétrica superior a $350 \mu \mathrm{S} / \mathrm{cm}$ ), o que coincide com a área de mais baixa pluviosidade. Praticamente a faixa que delimita CE superior a $500 \mu \mathrm{S} /$ $\mathrm{cm}$ corresponde à isoieta de $800 \mathrm{~mm}$. A isolinha de $750 \mu \mathrm{S} / \mathrm{cm}$ é praticamente coincidente com a isoicta $700 \mathrm{~mm}$ c, nessa sucessão de correlaçẫo, provavelmente, já no estado da Bahia, onde a isoieta atinge a $500 \mathrm{~mm}$, a CE será superior a $1.000 \mu \mathrm{S} / \mathrm{cm}$.

\subsection{2. - Relevo/Hidrografia}

A localização do poço de captaçấo dos aquaiferos fissurais mantém estreita relação com o relevo e a hidrografia.

No trabalho de COSTA (1986) foi concluido que os poços localizados nos vales apresentaram as maiores vazões, seguidos daqueles situados à meia encosta (terço inferior) e, por último, daqueles localizados no topo ou nos planaltos.

Esse fato pode ser explicado pois, no nordeste, a drenagem subterrânea é efluente na maior parte do ano, ou scja, ofluxo dessas águas é dirigido do rio para as encostas marginais, dai ser mais fácil a alimentação das fraturas localizadas nas proximidades dos rios. 
Jà no sudeste, o clima favorece a drenagem afluente, onde o escoamento sub-superficial se dirige das encostas para os rios, constituindo a descarga de base que garante a perenidade desses rios na época em que não chove.

O único problema para os poços situados nos vales, na região nordeste, é que fiçarão mais sujeitos à salinização nos casos em que o rio já se encontra salinizado, como foi narrado para a área oriental da região analisada.

\section{5. - SÍNTESE E CONCLUSÕES}

O estudo comparativo entre as condicionantes regionais e os resultados obtidos na perfuraçăo de poços em duas regiøes de caracteristicas morfo-climáticas muito distintas, embora com nítidas semethanças geologicas, permite tirar as seguintes conclusర̌es:

$\Rightarrow$ as caracteristicas quantitativas e qualitativas das águas subterrâneas em aquiiferos fissurais săo, de fato, extremamente condicionadas pelos fatores geológicos;

$\Rightarrow$ as diferenças qualitativas e quantitativas entre as águas subterráneas explotadas do aquífero fissural no nordeste e no sudeste do Brasil devem-se exclusivamente ao fator clima.

A primeira conclusão apenas corrobora todas as pesquisas já efetuadas no nordeste e que permitiram definir critérios técnicos para um melhor aproveitamento dos recursos hidricos subterrâneos de uma vasta área dessa regiăo.

Com efeito, desde a década de 60 os estudos ali desenvolvidos nortearam a locaçăo de poços tubulares priorizando captar zonas aquiferas constituidas por fraturas geneticamente abcrtas $\mathrm{c} \mathrm{cm}$ rochas que apresentassem menores possibilidades de salinização das águas armazenadas em suas fraturas.

Apenas constituía uma incoerćncia inexplicável o fato de rochas como o micaxisto e o filito apresentarem boas vazócs $\mathrm{e}$ altas taxas de salinização. No presente trabalho esse fato póde ser bem entendido por apresentarem essas rochas um comportamento dútil quando deformadas, sendo suas fraturas muito pouco espaçadas, o que confere ao aquifero uma grande homogeneidade pela intercomunicação das fraturas, justificando as elevadas vazões. Por outro lado, essas fissuras apresentam reduzida abertura, dificultando o fluxo e a conseqüente reno- 
vação das águas armazenadas, o que propicia uma maior salinização dessas águas. Jà as rochas graniticas, que apresentam um comportamento deformacional do tipo rúptil, possuem fraturas muito abertas porém extremamente espaçadas, dificultando a intercomunicação dos diferentes sistemas de fissuras, o que resulta em vazões reduzidas para esse tipo de rocha, apesar da maior permeabilidade de cada fratura isolada.

O clima nunca constituiu um critério técnico para locação de poços no nordeste pois as diferenças climáticas somente ocorrem em escala muito regional, como entre o litoral e o interior, sendo nula a sua influência quando se trata de escolher o local de um poço dentro de uma mesma zona climática.

Todavia, a análise de sua influência, tanto na potencialidade de um aquífero fissural, como na qualidade das águas ai contidas, pôde ser muito bem caracterizada no presente trabalho, justificando plenamente as diferenciaçőes constatadas nas caracteristicas das águas explotadas de aquifferos fissurais em um clima semi-árido, como no nordeste e $\mathrm{em}$ um clima tropical úmido como no sudeste. Com efeito, o clima tropical úmido do sudeste brasileiro contribui duplamente para melhorar as caracteristicas qualitativas: a maior pluviosidade implica em maiores volumes infiltrados, garantindo vazões mais elevadas; a intemperizaçẫo quimica facilitada por esse clima possibilita a formação de solos mais espessos que funcionam como aqüifero granular complementar, além de direcionar as àguas infiltradas para as fissuras do aqui ifero fissural que the embasa. Por outro lado, os maiores volumes infiltrados renovam mais facilmente as àguas armazenadas, impedindo a sua salinização.

O clima semi-árido, por sua vez, propicia menores infiltraçōes, reduzindo os volumes armazenados c dificultando a renovaçào das águas, com a consequente salinização das mesmas. A precipitação de sais resultante da intensa evaporação caracteristica desses climas é mais um fator que colabora com a má qualidade das águas subterrâneas nesse tipo de aquififero.

Em resumo, o clima é responsível năo apenas pelas reduzidas vazòes obtidas nos poços do nordeste, mas, também, pelo elevado teor de salinizaçāo das águas captadas nessa região. 


\section{6. - REFERÊNCIAS BIBLIOGRÁFICAS}

CETEC - Fundaçâo Centro Tecnológico de Minas Gerais - 1983 - "Diagnóstico Ambiental do Estado de Minas Gerais" - Belo Horizonte MG.

COSTA, Waldir D. - 1980 - "Fluxo através de fraturas" - Seminário apresentado no Curso de Pós-Graduaçâo da USP - SP.

1985 - "Avaliaçẫo dos crítérios de locação de poços em rochas cristalinas" - $1^{\circ}$ Simpósio Nacional de Águas Subterrâneas em Rochas Fraturadas - Belo Horizonte - MG - Anais da ABAS.

1986 - "Análise dos Fatores que atuam no Aquuifero Fissural - Área Piloto dos Estados da Paraiba e Rio Grande do Norte" - Tese de Doutorado - USP - SP (inédita).

COSTA, Walter D, - 1963 - "Hidrogeologia no Cristalino - Região Monteiro/Sumé-PB" Bol.da SBG - Núcleo de PE - Recife.

1965 - "Análise dos Fatores que influenciam na hidrogeologia do Cristalino" Rev. Água Subterrânea n 1 -Recife - PE.

1980 - "A hidrogeologia à luz da mecânica das rochas" Anais do $I^{\circ}$ Congresso da ABAS - Recife - PE.

CRUZ, W.B.da - 1974- -Estudo geoquímico preliminar das águas subterrầneas do nordeste do Brasil" - SUDENE; Sćric Hidrogeologia $n^{\circ} 8$ Recife-PE

LEAL, A.de S. - 1968 - "Consideraçర̌es sobre a circulação da água em rochas cristalinas e salinização em regiâo árida: Área de JuazeiroCuraça - BA" - SUDENE: Séric Hidrogeologia n' 24 - Recife - PE MENDES, G.M de A e SILVA JÚNIOR, H.de O - 1980 - "Identificação de áreas passiveis à exploraçăo de água subterrânea no sertăo pemambucano" - CONDEPE (Pub. Interna) - Recife - PE

REBOUÇAS, A da C - 1973 - "Le problema de l'eau dans la zone semiaride du Bresil" - Tese de Doutorado apresentada na Universidade de Strasbourg - França (inédita).

SIQUEIRA, L. - 1963 - "Contribuiçẵo da Geologia ả Pesquisa de Água Subterrainea" - SUDENE - Recife - PE.

SOUZA, S.M.T.de - 1995 "Disponibilidades Hidricas Subterrâneas no Estado de Minas Gerais" - HIDROSISTEMAS - COPASA - Belo Horizonte - MG. 


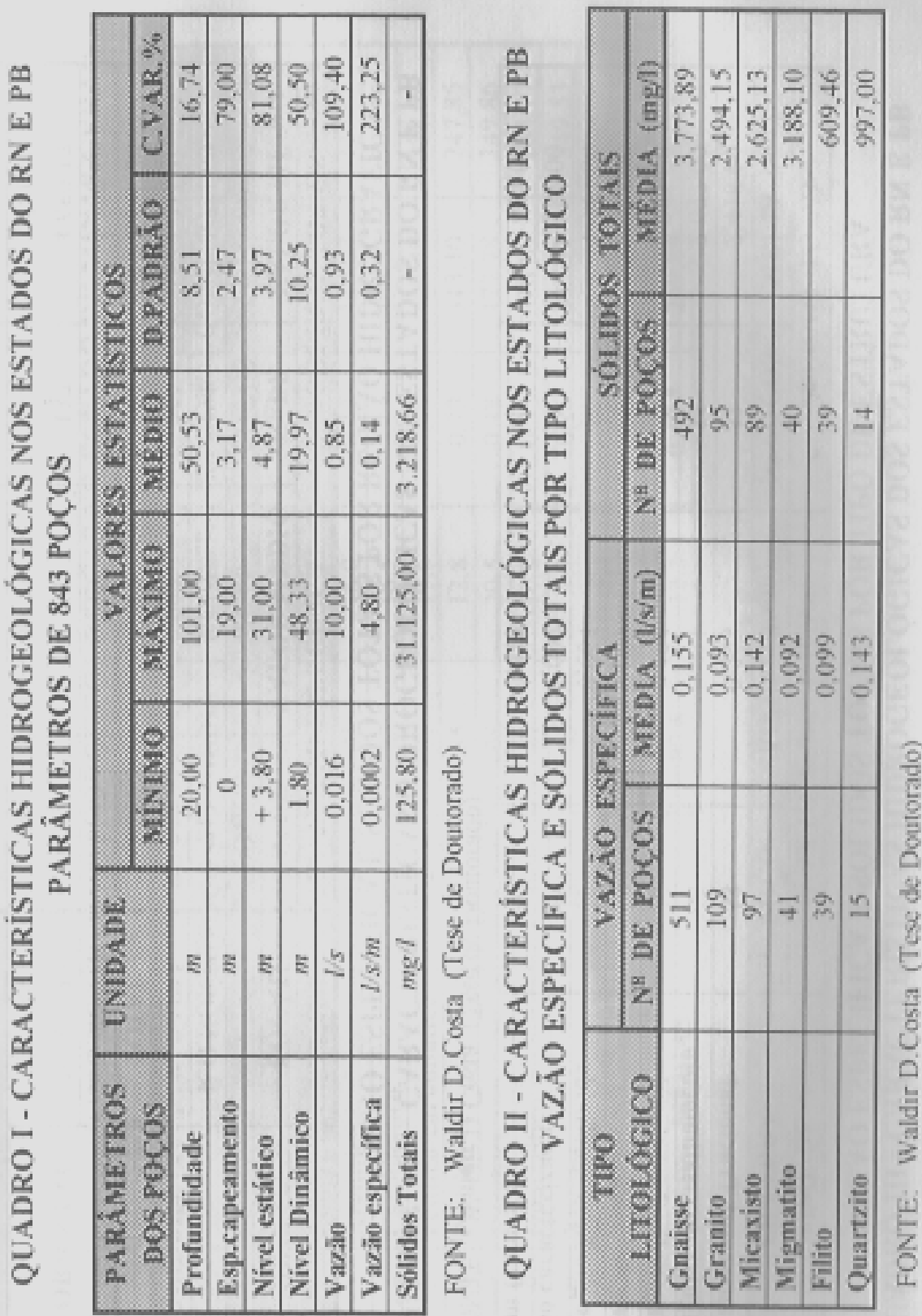




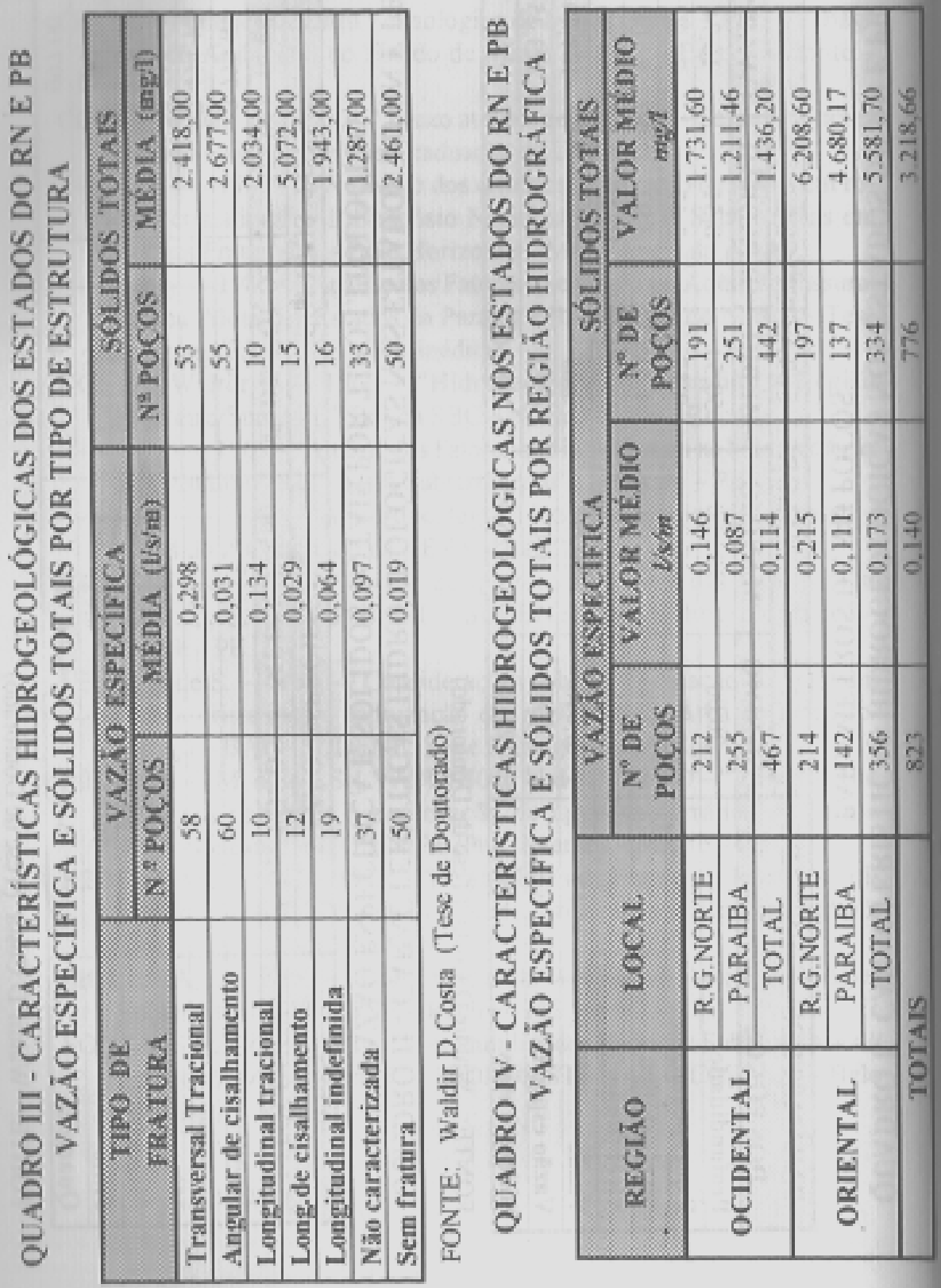




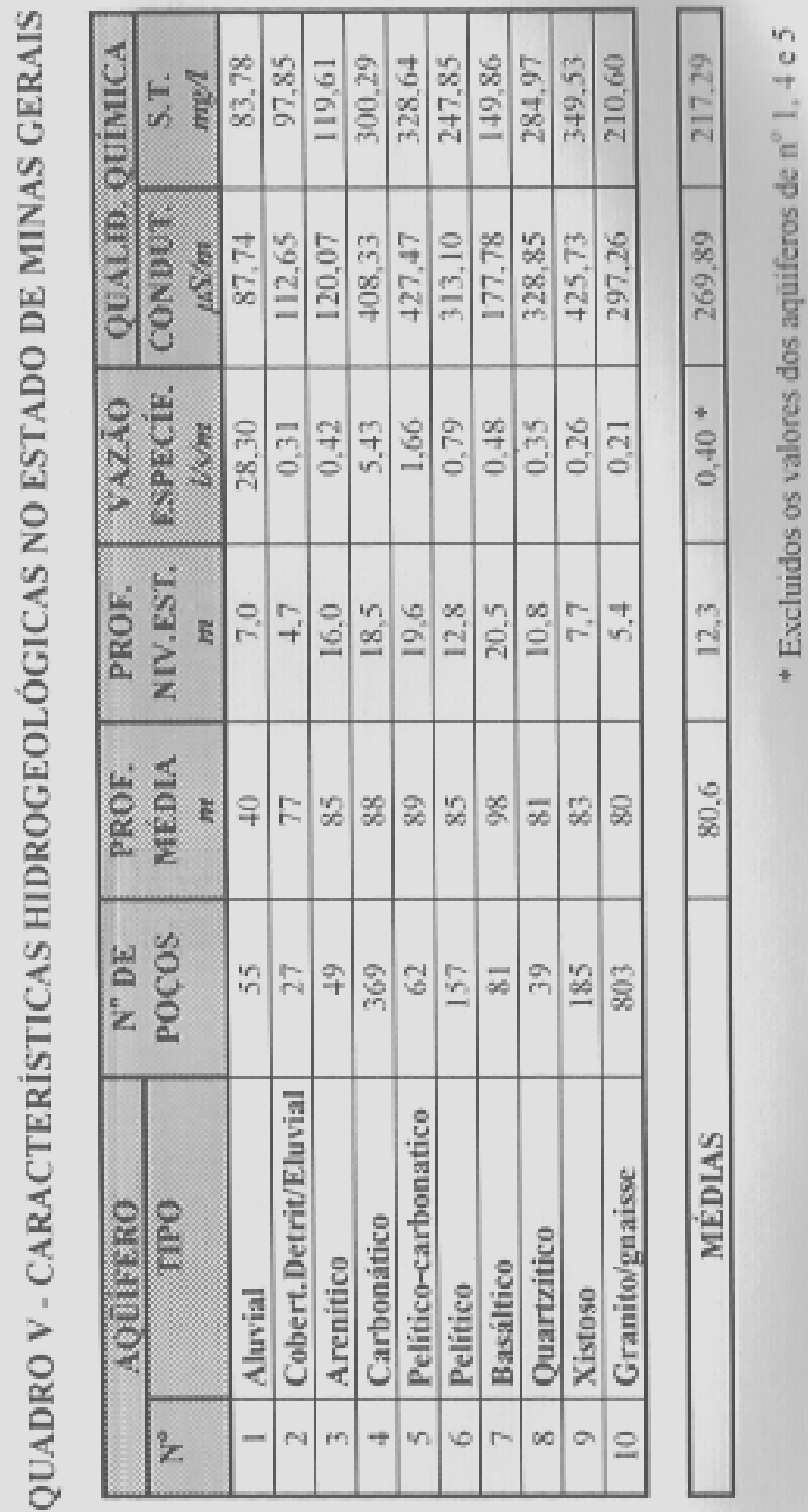




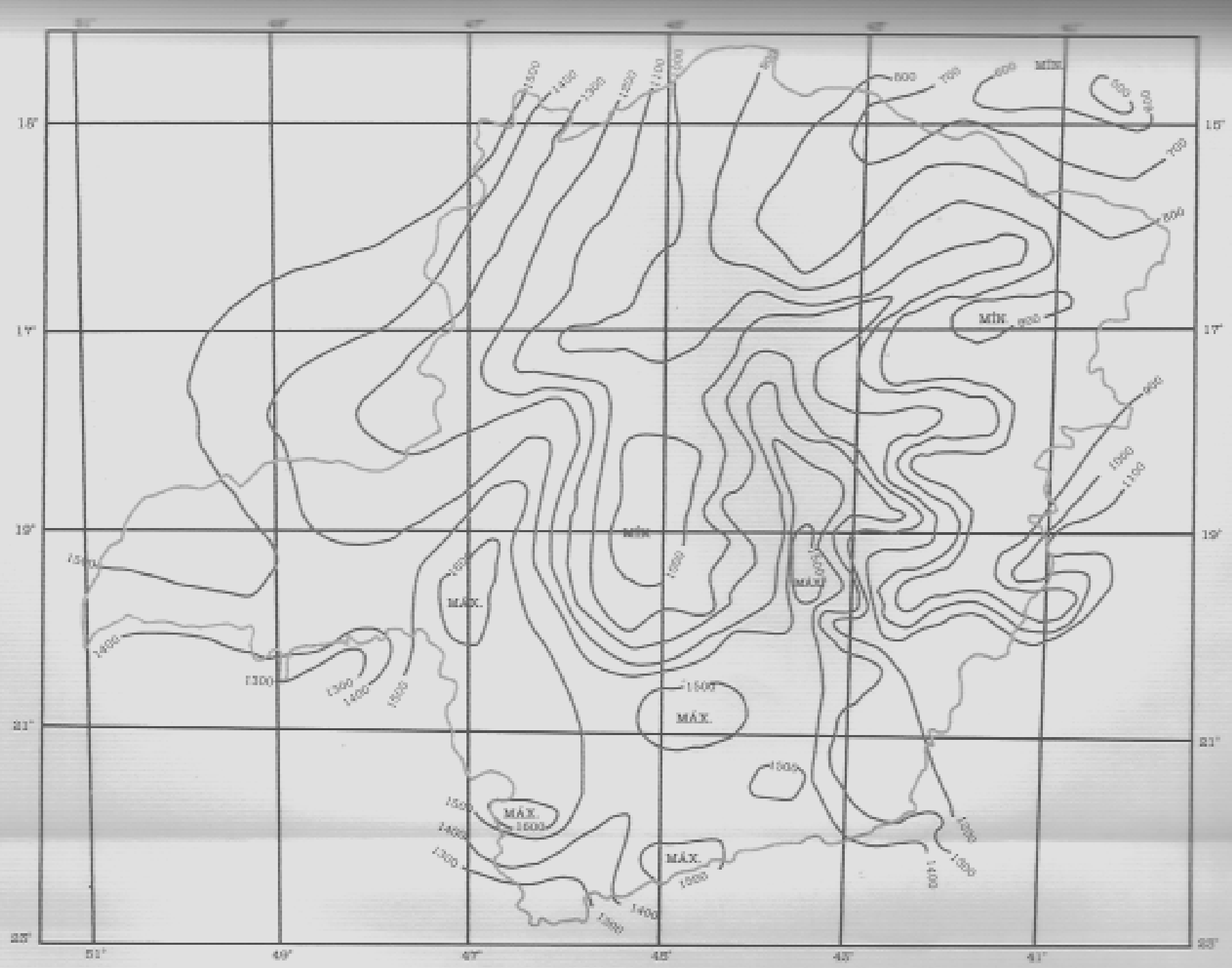

FONTE: CETRC -1983

ESCALA 1:7.000.000

\section{LEGRNDA}

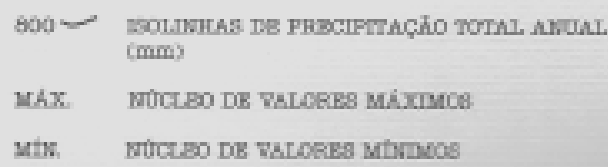

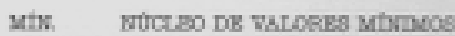




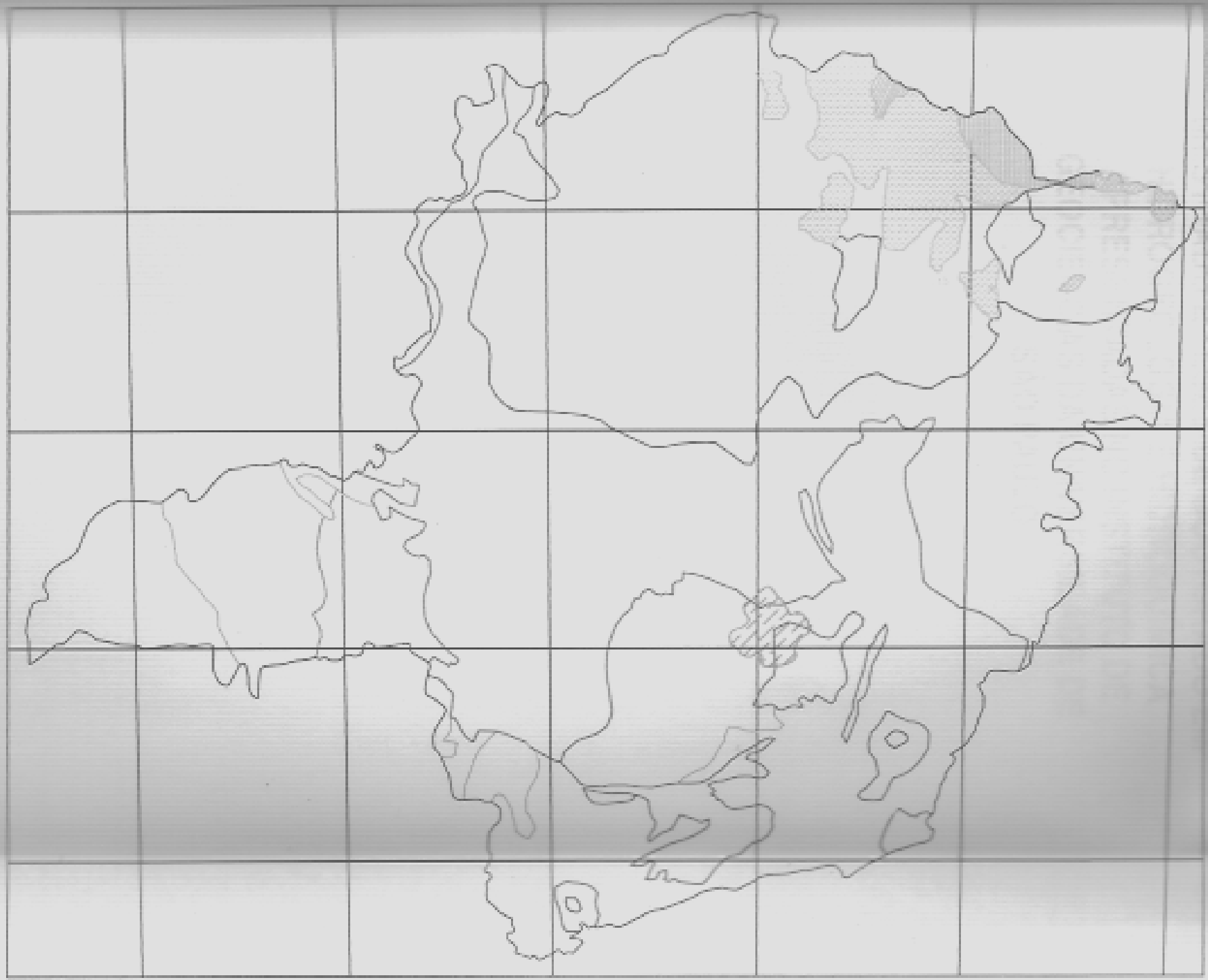

FONT'E: COPASA - 1995

LEGENDA

RRGLÃO METROPOLITANA DE BELO HORIZON'TE

ISOLINHA DE CONDUTTVIDADE BLÉTRICA.
BSCAI.A 1:7.000.000

VALORES DE CONDUTIVIDADE HLÉTRICA $(\mathrm{mS} / \mathrm{cm})$

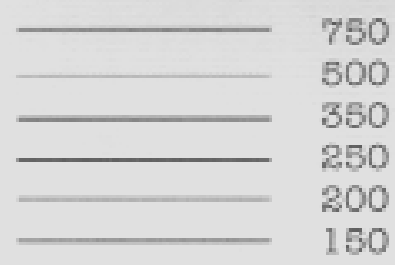

